\title{
EFFECT OF BACKREST CONTACT ON THE APPARENT MASS OF THE SEATED HUMAN BODY EXPOSED TO SINGLE-AXIS AND DUAL-AXIS EXCITATION
}

\author{
Yi Qiu and Michael J. Griffin \\ Human Factors Research Unit, Institute of Sound and Vibration Research, \\ University of Southampton, United Kingdom
}

\section{Introduction}

Contact with a backrest affects the apparent mass of the seated human body exposed to single-axis vibration excitation. ${ }^{1-2}$ With vertical excitation, a backrest tends to reduce the vertical apparent mass measured on the seat at frequencies less than the resonance frequency but increase the apparent mass at frequencies greater than the resonance frequency. A similar effect is observed with fore-and-aft excitation, with the first resonance in the fore-and-aft apparent mass measured on a seat increasing from $0.7 \mathrm{~Hz}$ without a backrest to $4 \mathrm{~Hz}$ with a backrest. ${ }^{3}$

This study was undertaken to compare the apparent masses of subjects seated with and without a backrest while exposed to single-axis and dual-axis vertical and foreand-aft excitation. It was hypothesised that during both single-axis and dual-axis excitation, the fore-and-aft and vertical apparent masses measured on a seat without a backrest would differ from those measured with a backrest.

\section{Methods}

Twelve male subjects sat in a normal relaxed upright posture with their hands on their laps and with average thigh contact on a rigid flat horizontal seat with and without a rigid flat vertical backrest secured to the ISVR 6-axis motion simulator. Subjects were exposed to random vibration $(0.2$ to $20 \mathrm{~Hz})$ with all 15 possible combinations of four vibration magnitudes $\left(0,0.25,0.5\right.$, or $1.0 \mathrm{~ms}^{-2}$ r.m.s. $)$ in the fore-and-aft and vertical directions. When exciting the body in both axes simultaneously, the two motions were uncorrelated. After mass-cancellation in the time domain, the forces on the seat were used to calculate the fore-and-aft and vertical apparent masses at the seat surface using singleinput single-output models.

\section{Results}

The medians of the moduli of the fore-and-aft driving point apparent masses of the 12 subjects with and without the backrest during single-axis fore-and-aft excitation $\left(a_{x}=0.5 \mathrm{~ms}^{-2}\right.$ r.m.s. $)$ and during dual-axis excitation $\left(a_{x}=0.5 \mathrm{~ms}^{-2}\right.$ r.m.s., $a_{z}=0.25,0.5$ or $1.0 \mathrm{~ms}^{-2}$ r.m.s.) are shown in Figure 1.

The medians of the moduli of the vertical apparent masses of the 12 subjects with and without the backrest during single-axis vertical excitation $\left(a_{z}=0.5 \mathrm{~ms}^{-2}\right.$ r.m.s. $)$ and during dual-axis excitation ( $a_{z}=0.5 \mathrm{~ms}^{-2}$ r.m.s., $a_{x}=0.25,0.5$ or $1.0 \mathrm{~ms}^{-2}$ r.m.s. $)$ are shown in Figure 2. 


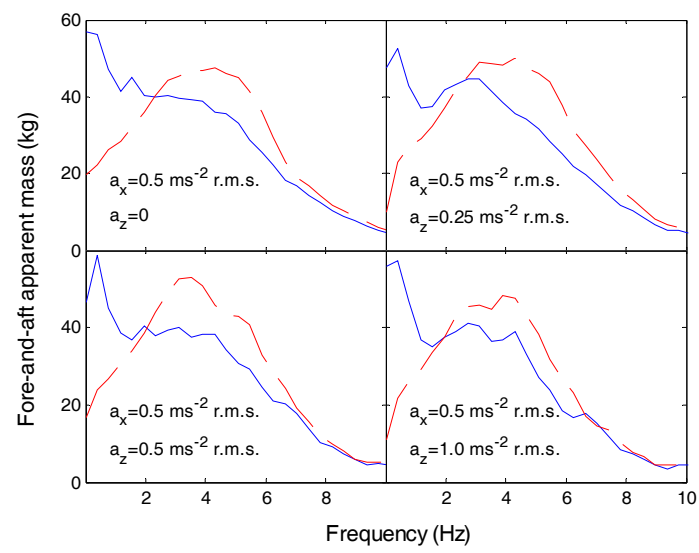

Figure 1 Fore-and-aft apparent mass: without backrest; - - - with backrest.

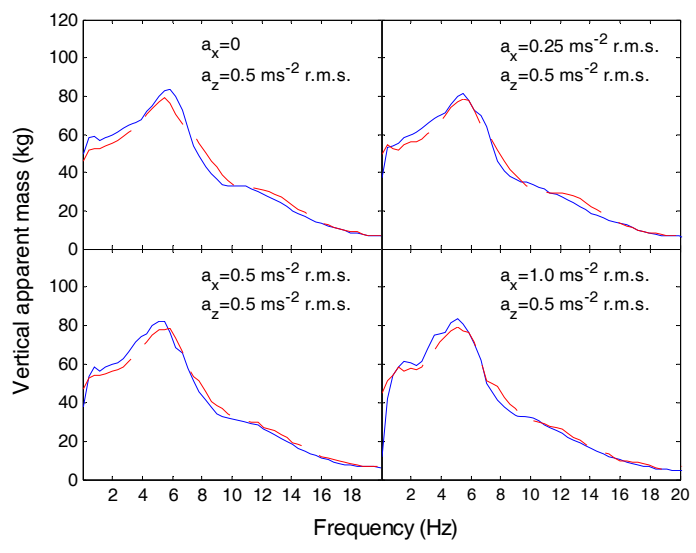

Figure 2 Vertical apparent mass: without backrest; - - - with backrest.

\section{Discussion}

With single-axis fore-and-aft excitation, the fore-and-aft apparent mass on the seat was greater without the backrest at the lower frequencies but greater with the backrest at the higher frequencies, consistent with previous studies. At two example frequencies in these ranges $(0.78$ and $3.91 \mathrm{~Hz})$ the differences were highly significant ( $p=0.002$ and 0.002 ; Wilcoxon). With dual-axis fore-and-aft and vertical excitation, there was a similar effect of the backrest on the fore-and-aft apparent mass with significant differences at the same frequencies for all three magnitudes of vertical excitation shown in Figure $1(p<0.006)$.

With single-axis vertical excitation, the backrest tended to affect the vertical apparent mass on the seat as previously reported. Although the simple rigid flat vertical backrest used here produced only small differences, the vertical apparent mass measured on the seat tended to decrease at the lower frequencies and increase at frequencies greater than the resonance frequency. With dual-axis fore-and-aft and vertical excitation, the effect of the backrest on the vertical apparent mass at the seat was similar to that with single-axis vertical excitation. At an example frequency less than the resonance frequency (i.e. $2.73 \mathrm{~Hz}$ ), the reduction in the vertical apparent mass on the seat was statistically significant with all four magnitudes of fore-and-aft excitation $(p<0.012$; Figure 2), but at an example frequency greater than the resonance frequency (i.e. $8.2 \mathrm{~Hz}$ ), there was no statistically significant difference.

\section{References}

1. Fairley, T.E. and Griffin, M.J. (1989). The apparent mass of the seated human body: vertical vibration. Journal of Biomechanics 22, 81-94.

2. Toward, M.G.R. and Griffin, M.J. (2009). Apparent mass of human body in the vertical direction: effect of seat backrest. Journal of Sound and Vibration. 327, 657-669.

3. Fairley, T.E. and Griffin, M.J. (1990). The apparent mass of the seated human body in the fore-and-aft and lateral directions. Journal of Sound and Vibration. 139 (2), 299-306. 